\title{
Respiratory health professionals call on MPs to vote to ban smoking in cars with children
}

\author{
Nicholas S Hopkinson chair ${ }^{1}$, Azeem Majeed professor of primary care ${ }^{2}$, John Britton professor of \\ epidemiology ${ }^{3}$, Andy Bush professor of paediatric respiratory medicine ${ }^{4}$, Jon Ayres professor of \\ environmental and respiratory medicine ${ }^{5}$, Martin McKee professor of European public health ${ }^{6}$, Trisha \\ Greenhalgh professor of primary health care $^{7}$, On behalf of 584 others
}

${ }^{1}$ British Thoracic Society Chronic Obstructive Pulmonary Disease Specialist Advisory Group, National Heart and Lung Institute, Imperial College, London SW3 6NP, UK; ${ }^{2}$ Imperial College London, London, UK; ${ }^{3}$ University of Nottingham, Nottingham, UK; ${ }^{4}$ National Heart and Lung Institute, London, UK; ${ }^{5}$ University of Birmingham, Birmingham, UK; ${ }^{6}$ London School of Hygiene and Tropical Medicine, London, UK; ${ }^{7}$ Queen Mary University of London, London, UK

Secondhand exposure to tobacco smoke is a major cause of ill health in children. ${ }^{12}$ Smoke inhalation damages the developing lung, and the Royal College of Physicians estimates that each year in the UK it is responsible for 300000 primary care contacts, 9500 hospital admissions, at least 200 cases of bacterial meningitis, and 40 sudden infant deaths. ${ }^{1}$ Most of this additional burden of disease falls on the more disadvantaged children in society, ${ }^{3}$ and all of it is avoidable. There is a strong consensus that children need to be protected from unnecessary hazards, that exposing children to tobacco smoke is unacceptable, and that removing this exposure is effective. ${ }^{2}$

Children in cars where a person is smoking are forced to inhale high amounts of tobacco smoke. ${ }^{4}$ As health professionals working to improve respiratory health, we welcome the amendment to the Children and Families Bill 2013 that allows the government to introduce legislation to ban smoking in cars where children are present. ${ }^{5}$

Objections that this legislation impinges on freedom assume that there is a right to force children to breathe tobacco smoke and the objectors seem to value this more highly than the children's right to breathe clean air. There are precedents for legislation to determine behaviour while driving, most obviously laws requiring the wearing of seatbelts and the use of child car seats, ${ }^{6}$ as well as the ban on mobile phone use while driving. Smoking in cars where children are present has been banned in other countries.

We urge MPs to support this important public health measure, which will protect the wellbeing of children now and in the future.

Competing interests: None declared.

Full list of signatories at: www.bmj.com/content/348/bmj.g1284/rr/ 685269.

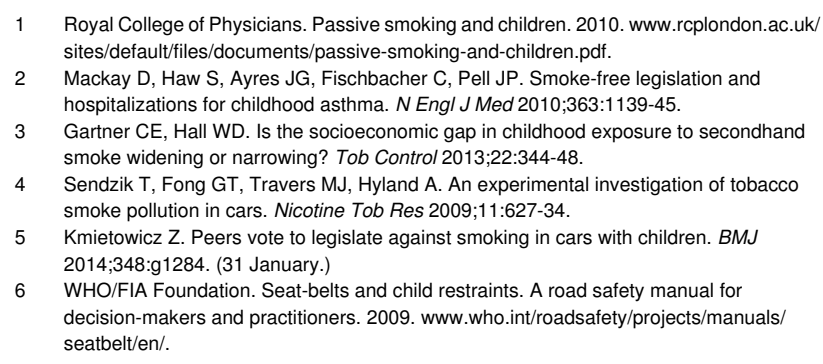

Royal College of Physicians. Passive smoking and children. 2010. www.rcplondon.ac.uk/ sites/default/files/documents/passive-smoking-and-children.pdf.

2 Mackay D, Haw S, Ayres JG, Fischbacher C, Pell JP. Smoke-free legislation and hospitalizations for childhood asthma. N Engl J Med 2010;363:1139-45.

3 Gartner CE, Hall WD. Is the socioeconomic gap in childhood exposure to secondhand smoke widening or narrowing? Tob Control 2013;22:344-48.

4 Sendzik T, Fong GT, Travers MJ, Hyland A. An experimental investigation of tobacco smoke pollution in cars. Nicotine Tob Res 2009;11:627-34.

5 Kmietowicz Z. Peers vote to legislate against smoking in cars with children. BMJ 2014;348:g1284. (31 January.)

6 WHO/FIA Foundation. Seat-belts and child restraints. A road safety manual for decision-makers and practitioners. 2009. www.who.int/roadsafety/projects/manuals/ seatbelt/en/. 